\title{
Examining the determinants of information systems utilization in the public sector of developing countries
}

\author{
Esmat A. Wahdain ${ }^{1, *}$, Ahmad Suhaimi Baharudin ${ }^{1}$, Mohammad Nazir Ahmad ${ }^{2}$ \\ ${ }^{1}$ School of Computer Sciences, University of Sciences Malaysia (USM), Gelogur, Penang, Malaysia \\ 2Faculty of Computing, University of Technology Malaysia (UTM), Skudai, Johor Bahru, Malaysia
}

\section{A R T I C L E IN F O}

\section{Article history:}

Received 4 June 2017

Received in revised form

15 September 2017

Accepted 22 September 2017

\section{Keywords:}

Technology acceptance model

Technology adoption

Public organizations

Organizational culture

Information systems utilization

\begin{abstract}
A B S T R A C T
There is plenty of research about information systems adoption and utilization in the extant literature; however, most of it is focused on the context of developed countries. Less attention has been paid for studying the utilization determinants on the context of public organizations in the least developed countries. This paper tries to shed some light on IS utilization determinants in a $3^{\text {rd }}$ world country with special economic and cultural characteristics, Yemen. The study amended the well-known technology acceptance model (TAM) by adding the factors: Organizational culture, Individual factors, Gender, and Perceived Personal Benefit to the original version. Data was collected quantitatively from 139 employees of the Ministry of Social Affairs and Labour (MoSAL) - Yemen, whom their jobs involve using IT. Using SmartPLS software, PLS-SEM method was used to check the reliability of measurement model, and to assess the structural model. The results provided a statistical evidence of the proposed hypotheses, as organizational culture was influential in deciding perceived usefulness and perceived personal benefit for the respondents, which is consistent with previous research. The results also demonstrated the role of gender in moderating both hypothesized relationships; this emphasized the importance of gender in the context of the study and similar contexts, which was rarely focused on in the previous research. Finally, the model showed a good predictive power since $65 \%$ of the focal factor, behavioral intention, was explained by its relationships with the other factors.
\end{abstract}

(C) 2017 The Authors. Published by IASE. This is an open access article under the CC BY-NC-ND license (http://creativecommons.org/licenses/by-nc-nd/4.0/)

\section{Introduction}

With the rapid diffusion of IT in the last 20 years, many public-sector organizations in developing countries, including Yemen, have resorted to it as an enabler to make big strides towards optimal efficiency, higher effectiveness, and improved quality services. In line with this, Yemeni public sector has witnessed several IT implementation projects in different organizations, including the Ministry of Social Affairs and Labour (MoSAL), Hadhramout province's branch. Many of those implementations, however, failed to realize the improvements sought after.

In fact, the disappointing outcomes of a considerable number of IT projects are a global phenomenon that occurs in developing and

\footnotetext{
* Corresponding Author.

Email Address: esmat_wahdain@yahoo.com (E. A. Wahdain) https://doi.org/10.21833/ijaas.2017.011.009

2313-626X/C 2017 The Authors. Published by IASE.

This is an open access article under the CC BY-NC-ND license

(http://creativecommons.org/licenses/by-nc-nd/4.0/)
}

developed countries similarly. 2014 CHAOS report revealed that only $16.2 \%$ of the projects implemented in USA were successful, in terms of fulfilling the deadline and budget constraints, while astonishingly, $31.1 \%$ of the projects were failed projects, means that they were cancelled before ever get completed. The other $52.7 \%$ were challenged projects, which are the projects that completed but over budget, over deadline, with less features that what initially specified (SGII, 2014). These poor success rates become poorer when public sector organizations are surveyed. RAEng (2004) reported that $84 \%$ of government IT projects ended up with some level of failure.

Over the last two decades, there has been a plenty of research aimed to identify the causes of such frustrating outcomes, for example, (Nawi et al., 2011) suggested that ICT failure factors can be classified as follows: top management, project management, technology factors, complexity/size, process and organizational factors. (Yeo, 2002) categorized the failure factors into three categories: context-driven (cultural, organizational, and 
leadership related factors), content-driven (business process, technology related factors), and processdriven (strategic planning, change management).

Although all studies have been trying to tackle the issue from different angles, there is a consensus that productivity leaps promised by IT won't be achieved unless IT tools are widely utilized (Dijk, 2009).

That brings us to the notion of "user acceptance", which is considered as one of the most influential determinants of ICT projects success or failure. SGII (2014) showed that lack of user input was found to be the most prominent factor that lead to challenged IT projects rather than successful ones, similarly, user involvement was the main reason of projects success in 2015's report (TSG, 2015).

There is a large body of literature about user acceptance of technology, however, studies that focused on technology acceptance in public sector are relatively few, and even fewer studies have focused on the context of Arabic context, which represents major part of the developing, third world countries with different cultural and social characteristics than what most studies have covered. Wahdain et al. (2014) reviewed several studies that presented different models to investigate user acceptance of technology in public organizations in different developing countries, and explained the reasons why those models are not applicable in the current case study.

In spite of the significance of the above reviewed research works, the researcher contends that none of them is compatible with the context being investigated, since applying a particular theory in a particular case needs sufficient knowledge about that context. Therefore, personal observations were very important to determine what theory better fitted the studied case than others, and furthermore, to decide what amendments should be made to that model or theory to provide better reliability, and that's what this study tries to achieve.

It is all-important to understand the reasons that cause users to accept any newly adopted Information System or to resist it. In the current case, the case of Yemeni public organization; it is also important to understand the role that organizational culture plays in the adoption process.

Since the government endeavors increasing female employment, it is important to learn about the impact of the current organizational culture on female employees' acceptance, and subsequently, usage of behavior of IT.

That is because in the current common practices regarding IT positions, women's jobs are usually restricted to data entry or word processing. This paper serves two purposes, the first is to present a reliable model that examines the determinants of user acceptance of IT among the employees of a Yemeni public sector organization namely MoSAL. The second purpose is to explain how this model was tested, and to present and discuss the results that showed the reliability and predictability of the model.

\section{Theoretical background and research model}

\subsection{User acceptance theories and TAM}

User Acceptance can be defined as "the demonstrable willingness within a group of users to use information technology for the functions that it is planned to support".

Due to the large scientific concern about the significance of attitude, acceptance, and user behavioral intention in determining the behavior of an individual, there have been many theories that tried to understand, elucidate and anticipate users' behaviour, and most of these theories were adopted in the field of technology adoption to explain the acceptance of new technologies. Theory of Reasoned Action was one of the earliest theories in this field, it suggests that individual's intention to perform an action depends on the individual's expectations about the outcomes of that action (attitude), and the social pressure that the individual perceive towards doing or not doing that action (subjective norm). Also, the theory posits that if an individual intends to do the action then it is most likely he will do it (Fishbein and Ajzen, 1975). Ajzen (1991) argued that strong behavioral intentions do not necessarily lead to actual behavior, especially in the cases whereby the user has incomplete control over performing the behavior, therefore he added the construct "perceived behavioral control" to establish new theory called: The Theory of Planned Behavior. Davis (1989) presented one of the most influential theories in Information systems research, the Technology Acceptance Model (TAM), proposed that whenever a new technology is presented to users, their decision to whether utilize or not utilize the new technology depends on two belief factors, Perceived usefulness and Perceived ease of use.

TAM was essentially designed to model the acceptance of IT/IS by potential users. Its main purpose was to predict IT/IS acceptance and pinpoint any design flaws before the system were launched and utilized by the users (Chandio, 2011).

\subsection{Research model}

The current study employed TAM to examine technology acceptance in the Yemeni public sector, this is because:

- TAM is a parsimonious, predictive, and powerful model to assess the acceptance of IT by users (Venkatesh and Davis, 2000).

- It is essential for anyone interested in studying users' acceptance of technology to understand TAM (Chuttur, 2009).

- TAM offers flexibility, because the construct "external variables" can be comprised of different extrinsic variables that fit to every single case.

The research model (Fig. 1) was derived from related extant literature, together with the authors' 
observation-based assumptions about the factors that influence employees' acceptance of new IT tools and IS in the public sector of Yemen. TAM was amended as follows:

- The construct "perceived personal benefit" was appended as an additional belief factor. This factor was introduced by a study that extended TAM to investigate PC utilization in the public-sector agencies in developing countries (Hamner and Qazi, 2009). The researchers found that personal benefit, which was expressed by the financial remuneration that employees receive for using PCs, had a positive effect on the behavioral intentions of users, and subsequently, on the actual use of PCs. This is very similar to the case of the present study, whereby employees in some departments of MoSAL are financially rewarded for using computers or information systems. The utilization of computers and information systems in those departments is notably better than in other departments, where employees do not receive any financial compensation.

- The TAM construct "external variables", was replaced by two variables that are believed to impact the user acceptance in the case study, namely: "organizational culture" and "individual factors". Previous research has shown the significant influence of OC in the employees' attitude (Dubey et al., 2017) and that the absence of favorable organizational culture hurdles the effective utilization of computers (Igbaria and Chakrabarti, 1990), while the presence of positive, facilitating culture increase technology utilization in that organization (Igbaria and Chakrabarti, 1990). Also, previous studies found that individual factors were influential in determining users' attitude towards using IT (Hamner and Qazi, 2009; $\mathrm{Xu} \mathrm{Lu}, 2008$ )

- The gender was appended as a moderator to two causal relationships, the first one links organizational culture and perceived usefulness, and the other one links organizational culture and perceived personal benefit. Gender issue, has been drawing growing attention from the Yemeni government, and seeking out the improvement of women's education and employment is one of the aspects of this attention. We believe that there are some negative conceptions regarding female employees in the Yemeni public organizations, as for IT jobs, it is common that female employees are usually assigned routine, simple tasks that do not need high skills or intelligence, such as data entry and word processing, regardless of their actual skills, or qualifications. This was echoed in IT acceptance among female employees, furthermore, the misconception that females are not qualified enough to occupy high level IT jobs has an impact on the benefits that women can earn by using IT. This research aims, to evaluate the importance of gender in determining IT acceptance among employees in the public sector of Yemen.
- Finally, the actual use construct was excluded from the research model, this is to avoid the unreliability that self-reporting can cause. In most cases, the measurement of actual use construct is based on users' self-reporting about their actual use; especially when there is no objective usage metrics (electronic log for example) are available, like the case that is being investigated here. Therefore, it is common in TAM studies that aim to predict IT/IS acceptance to measure acceptance by behavioral intention rather than actual usage (Chandio, 2011; Mathieson et al., 2001). This is also consistent with the findings of several previous studies that showed that TAM basic constructs perceived usefulness, and perceived ease of use have direct relationship with behavioral intention, but not with the actual usage (Gefen and Straub, 2000; Jarvenpaa et al., 2000).

The relations among different constructs are being hypothesized as follows:

Hypothesis1: Organizational Culture has a positive effect on the Perceived Usefulness.

Hypothesis 2: Organizational Culture has a positive effect on Perceived Personal Benefit.

Hypothesis 3: Individual Factors have positive effect on the Perceived Ease of Use.

Hypothesis 4: Individual Factors have positive effect on the Perceived Personal Benefit.

Hypothesis 5: Perceived Ease of Use has significant positive effects on the Perceived Usefulness of IT tools.

Hypothesis6: Perceived Usefulness has significant positive effect on Attitude towards using IT tools.

Hypothesis7: Perceived Ease of Use has significant positive effect on Attitude towards using IT tools.

Hypothesis 8: Perceived Personal Benefit has a positive effect on Attitude toward use.

Hypothesis 9: Perceived Usefulness has significant positive effect on Behavioural Intention to use. Hypothesis 10: Attitude towards using the IT tools has significant positive effects on Behavioural Intention to use.

Hypothesis 11: The positive relationship between Organizational Culture and Perceived Usefulness is stronger in case of men than it is in the case of women.

Hypothesis 12: The positive relationship between Organizational Culture and Perceived Personal Benefit is stronger in case of men than it is in the case of women.

\section{Methodology}

\subsection{Research instrument}

A questionnaire was developed to collect the primary data of this research. The questionnaire was initially divided into two parts, and a third section was added as it will be explained later. 
First part solicits the following demographic features of the respondents: Gender, Age, along with the components of the formative construct
Individual Factors: Educational level, Duration of computer training and Computer skills.

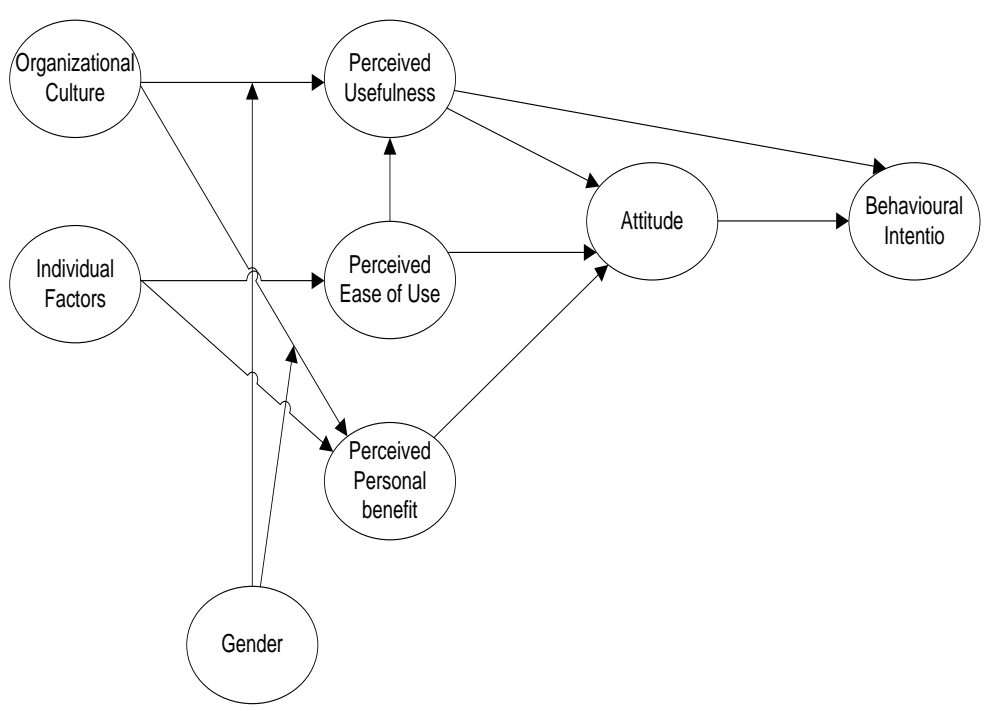

Fig. 1: Research model

The second part consisted of number of statements that reflects model constructs. A fivepoint Likert scale was used to assure sufficient discrimination. Measurement items for each construct were adopted from related literature, Questionnaire items are shown in Table 1.

\subsection{Content validation}

After that, the questionnaire was revised by 5 experts from different disciplines including (IT, Statistics, and social sciences) this is important to refine the questionnaire and get useful suggestions from well experienced people. Based on the strong recommendations made by the experts, a third part was added to the questionnaire, which was dedicated for the respondents' recommendations and suggestions. The resulted questionnaire was then used to conduct the pilot study.

\subsection{Sampling}

The study targeted the employees of the ministry of social affairs and labour, that's because it is one of the biggest ministries in Yemen in terms of: budget, number of employees and number of beneficiaries. It is also one of the few ministries that experienced several IS Implementations in the last two decades.

The respondents are employees in the ministry whom their jobs require dealing with IT. The total number of employees in the Ministry's branch of Hadhramout province is 470 employees, only 180 of them use IT in their jobs, and those represent the targeted population of the study.

According to Krejcie and Morgan (1970) table, we need to distribute 123 questionnaires, so, 170 questionnaires were distributed, 12 of them never returned, 19 were answered with some missing data, and 139 were completed properly. That resulted in almost $82 \%$ response rate which is relatively high.

\subsection{Data collection procedure}

Since the respondents of the questionnaire are Arabic natives, the questionnaire was translated to Arabic by a certified translator prior to distribution. The questionnaire was then sent to a pre-test sample of 30 respondents, who answered the questionnaire electronically; the questionnaire was prepared using google forms, and was sent to the respondents' Facebook accounts, this is to serve two purposes, firstly: to test the reaction of the respondents to the questionnaire, in terms of clarity, logical flow, and whether there is any confusion or ambiguity or not; and secondly to conduct a pilot study to assess the reliability of measurement model, and to evaluate the predictive power of underlying model. The pilot study confirmed the reliability of the measurement model, and the model showed good predictive capability. Pilot results were published (Wahdain and Ahmed, 2015).

\section{Data analysis}

\subsection{Measurement model testing}

Two types of measurement model evaluations are performed, internal consistency, which is tested by two values: the item loading, and the composite reliability; and the construct validity which contains two tests: the convergent validity and discriminant validity.

\subsubsection{Internal consistency}

Internal consistency in this research is examined by the loading of each measure with its related constructs and by the composite reliability instead of Cronbach's alpha which is widely used, this is to avoid the limitations of Cronbach's alpha pointed to by Hair (2014), which is the assumption of 
indicators' equal reliability, and the sensitivity to the number of items in the scale. As a general rule, the indicator loading should be $\geq 0.7$ Hair et al. (2011), but also the indicator with a loading between 0.40 and 0.70 should be kept and only be considered for elimination if removing this indicator causes an increase in the value of composite reliability above the proposed threshold value (Hair et al., 2011). The value of composite reliability, on the other hand must be from 0.60 to 0.70 in the case of exploratory research, and from 0.70 to 0.90 in more advanced research stages, to be considered as satisfactory, while values $<0.60$ show a lack of reliability (Hair et al., 2011). Table 1 summarizes the results that were revealed after running the PLS algorithm, both: item loadings and composite reliability assured the internal consistency of the measurement model.

\subsubsection{Construct validity}

Two tests of construct validity, were conducted, the first is the convergent validity, which is measured by the Average Variance Extracted value (AVE), hence an (AVE) $\geq 0.5$ is desirable (MacKenzie et al., 2011).

Table 1 shows that all constructs fulfill the condition of convergent validity (Awang, 2012). The second test is the discriminant validity, the aim of discriminant validity is to evaluate whether the indicator of a given construct are distinct from other constructs' indicators (MacKenzie et al., 2011). One way to test discriminant validity is to check if there is any cross-loading items, cross loading can be obtained easily by generating the cross loadings report under the quality criteria menu in SmartPLS, cross loading items indicates insufficient discriminant validity (Farrell and Rudd, 2009), and as shown in Table 2 below, there is no cross loading between indicators of the construct, and the indicators of each construct are clearly distinguishable from other constructs' indicators. Both tests have proven the validity of the research model.

\subsection{Descriptive analysis}

This section encloses the analysis of demographic data acquired; Table 3 summarizes the demographics of the sample.

Seemingly, most of the participants are males (67\%), however, considering the context being studied, which is a public sector organization in a country where women employment is low (in 2014, International Labor Organization reported that only $26 \%$ of the total Yemeni labour force are female (ILO, 2014)) the percentage of female participants $(33 \%)$ is considered good, as it reflects the real situation in the Yemeni context. Moreover, this percentage provides good foundation to investigate about the moderation effect of gender to the relationships between OC and both PU and PPB.

Referring again to Table 3, the age group of (2635 years), is the largest one, representing more than half of the sample (52\%), this is good for the research, because this group represents the new generation of employees, who are more contacted with IT and ICT technologies than the older employees, so they are expected to participate more effectively in a research that study IT related issues. This can be also said about the second age group (36-45) which represents (35\%) of the participants, opinions of this category are valuable, because they are mature and experienced, and many of them witnessed some of IS implementations, moreover, most of the middle managers are from this age group.

Table 1: Items' loadings, CR and AVE of all constructs

\begin{tabular}{|c|c|c|c|c|c|}
\hline Construct & Code & Items & Loading & CR & AVE \\
\hline \multirow{5}{*}{$\begin{array}{l}\text { Perceived ease of } \\
\text { use(PEOU) }\end{array}$} & PEOU1 & I found it easy to let the system do what I wanted it to do. & 0.913 & \multirow{3}{*}{0.9315} & \multirow{3}{*}{0.8193} \\
\hline & PEOU2 & It was easy for me to be skilful at using the system. & 0.907 & & \\
\hline & PEOU3 & I found that the system is easy to use. & 0.895 & & \\
\hline & PU1 & Using the system in my job enabled me to achieve tasks faster & 0.753 & \multirow{7}{*}{0.9330} & \multirow{7}{*}{0.7003} \\
\hline & PU2 & Using IT improved my performance in job & 0.881 & & \\
\hline \multirow{5}{*}{ Perceived usefulness(PU) } & PU3 & Using IT in my job improved my productivity & 0.875 & & \\
\hline & PU4 & Using IT increased my effectiveness on the job & 0.911 & & \\
\hline & PU5 & Using IT made it easier to do my job & 0.864 & & \\
\hline & PU6 & I found that IT useful in my job & 0.718 & & \\
\hline & BI1 & I intend to use IT when it becomes Available & 0.893 & & \\
\hline \multirow[t]{3}{*}{ Behavioral intention(BI) } & $\mathrm{BI} 2$ & $\begin{array}{c}\text { If I were asked to articulate my opinion of IT in job, I plan to say } \\
\text { something affirmative }\end{array}$ & 0.903 & \multirow[t]{3}{*}{0.9370} & \multirow[t]{3}{*}{0.8321} \\
\hline & $\mathrm{BI} 3$ & In the future, I intend to use IT routinely & 0.940 & & \\
\hline & AT1 & In my opinion it would be very desirable to use IT & 0.814 & & \\
\hline \multirow[t]{2}{*}{ Attitude toward use (AT) } & AT2 & Using IT would be interesting to me & 0.896 & \multirow[t]{2}{*}{0.8948} & \multirow[t]{2}{*}{0.7396} \\
\hline & AT3 & I would like to use IT & 0.867 & & \\
\hline \multirow{3}{*}{$\begin{array}{l}\text { Perceived Personal Benefit } \\
\text { (PPB) }\end{array}$} & PPB1 & Use of IT gives me the opportunity to earn more & 0.813 & \multirow{3}{*}{0.9053} & \multirow{3}{*}{0.7615} \\
\hline & PPB2 & The magnitude of financial compensation for using IT is justified & 0.918 & & \\
\hline & PPB3 & Use of IT will make my job more secure & 0.884 & & \\
\hline \multirow{4}{*}{ Organizational Culture (OC) } & 0C1 & In my organization using of IT is helpful in getting promotion & 0.787 & \multirow{4}{*}{0.8627} & \multirow{4}{*}{0.6114} \\
\hline & OC2 & My co-workers always help me using IT at job & 0.746 & & \\
\hline & OC3 & Management of my organization induces me to use IT in my job & 0.776 & & \\
\hline & OC4 & with the IT provided to me, doing my job became easier & 0.817 & & \\
\hline
\end{tabular}


Table 2: Cross loading

\begin{tabular}{ccccccc}
\hline & AT & BI & PEOU & OC & PPB & PU \\
\cline { 2 - 7 } AT1 & 0.8142 & & & & & \\
AT2 & 0.8964 & & & & & \\
AT3 & 0.8672 & & & & & \\
BI1 & 0.6091 & 0.8925 & & & & \\
BI2 & 0.6891 & 0.9034 & & & & \\
BI3 & 0.7163 & 0.9400 & & & & \\
PEOU1 & 0.6764 & 0.6237 & 0.9134 & & & \\
PEOU2 & 0.7133 & 0.5262 & 0.9075 & & & \\
PEOU3 & 0.6075 & 0.6391 & 0.8945 & & & \\
OC1 & 0.2976 & 0.226 & 0.2499 & 0.7871 & & \\
OC2 & 0.3327 & 0.2947 & 0.2646 & 0.7461 & & \\
OC3 & 0.3383 & 0.2554 & 0.2269 & 0.7761 & & \\
OC4 & 0.4694 & 0.4322 & 0.4157 & 0.8167 & & \\
PPB1 & 0.6088 & 0.5901 & 0.7213 & 0.3850 & 0.8128 & \\
PPB2 & 0.7143 & 0.4820 & 0.6900 & 0.4510 & 0.9177 & \\
PPB3 & 0.7222 & 0.4696 & 0.5611 & 0.4402 & 0.8841 & \\
PU1 & 0.4994 & 0.4623 & 0.3803 & 0.6265 & 0.4807 & 0.7530 \\
PU2 & 0.6793 & 0.6896 & 0.5492 & 0.5037 & 0.5856 & 0.8815 \\
PU3 & 0.5205 & 0.6599 & 0.4823 & 0.4876 & 0.4264 & 0.875 \\
PU4 & 0.6578 & 0.6948 & 0.5896 & 0.5481 & 0.6112 & 0.9108 \\
PU5 & 0.5333 & 0.5027 & 0.5062 & 0.5253 & 0.5399 & 0.8643 \\
PU6 & 0.5639 & 0.7178 & 0.5681 & 0.2177 & 0.4669 & 0.7181 \\
\hline
\end{tabular}

Education-wise, most of the employees of MoSAL are either bachelor degree holders or secondary school or diploma graduates, this is reflected precisely in the sample of participants, where almost half of them (49\%) were bachelor holders. Hence, the number of post graduate employees is notably few; this is consistent with the reality, where the number of post graduate employees in our ministry branch office, at the time of conducting this study, is about 10 employees only.

On the other hand, it seems that most of the employees have decent computer training, about $74 \%$ of the respondents have at least one month of computer training, while $12 \%$ of the employees wasn't involved in any computer training sessions, although the percentage looks low, it must be taken into consideration since all those employees have been using IT in their jobs without being trained adequately, which might have negative impact on the job performance and outcomes.
As regard to the computer proficiency, most participants classified themselves as beginners, even for the basic skills category. It is understandable that most employees are beginners in the advanced skills category, which includes: networking, programming and maintenance, but it is surprising to have 62 participants (about 45\%) who categorize themselves as beginners in the basic windows operations given that $74 \%$ of the employees have at least one month of training.

This relatively low level of computer skills, however, did not affect the perceived ease of use for the employees, this can be attributed to the proliferation of computers and IT in general, which has created a widespread perception, not only among the employees, but also among the people in the society in general, that the computers and information technology tools are easy to learn and use, even for those who are currently have low computer skills; Fig. 2 depicts the computer skills of the studied sample.

Table 3: Respondents demographics

\begin{tabular}{ccc}
\hline Gender & Number of respondents & Percentage \\
\hline Male & 93 & $67 \%$ \\
Female & 46 & $33 \%$ \\
Total & 139 & $100 \%$ \\
\hline Age groups & Number of respondents & Percentage \\
\hline$<25$ & 8 & $6 \%$ \\
$26-35$ & 72 & $52 \%$ \\
$36-45$ & 49 & $35 \%$ \\
$>45$ & & \\
Total & 10 & $7 \%$ \\
Educational Level & 139 & $100 \%$ \\
\hline Below secondary school & Number of respondents & Percentage \\
Secondary school or Diploma & 13 & $9 \%$ \\
Bachelor degree & 57 & $41 \%$ \\
Post graduate & 68 & $49 \%$ \\
Total & 1 & $1 \%$ \\
\hline Duration of computer Training & Number of respondents & Percentage \\
\hline No Training at all & 17 & $12 \%$ \\
1-4 weeks & 19 & $14 \%$ \\
1-3 months & 50 & $36 \%$ \\
$>$ 3 months & 53 & $38 \%$ \\
Total & 139 & $100 \%$ \\
\hline
\end{tabular}




\subsection{Structural model assessment}

The next step is to perform path analysis. Hence, three values are used to assess the structural model, namely: the path coefficient $\beta$, P-value, and coefficient of determination R2. R2 provides a measurement of the predictive power of the model, that is, how well observed results are reproduced by the model, as the percentage of the variance of outcomes interpreted by the model (Ifinedo, 2011; Steel and James, 1960). $\beta$ examines the possible causal relationship between the constructs in the structural model, and it indicates the strength of such linkage(Ko et al., 2005; Shipley, 2000). For the statistical hypothesis testing, the p-value is used as an indicator of the statistical significance; however the software used cannot calculate the p-value, so, the $p$-value was calculated as a function of t-value, which is resulted by running the bootstrapping procedure.

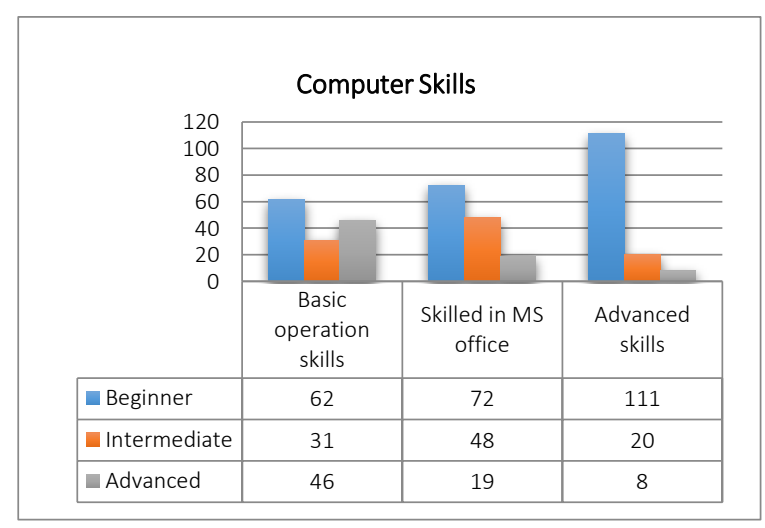

Fig. 2: Computer skills of respondents

Hence, the guidelines of (Chin, 1998) were followed, that is, the path significance can be evaluated by t-test values, normally, if the t-value is $>2$ that reflects the path significance. Additionally, if p-value $<0.05$, that means that the related hypothesis is supported by the model (Ifinedo, 2011). Hair et al. (2011), presented more detailed significance criteria, that is: if the $\mathrm{t}$-value $=1.65$ then the significance level is $10 \%$, if $\mathrm{t}$-value $=1.96$ then the significance level is $5 \%$ (supported hypothesis), and if $\mathrm{t}=2.58$ then the significance level is $1 \%$ (higher level of significance shows that the hypothesis is fully supported statistically).

Table 4 reports the results of the following: (1) path coefficient $(\beta)$ between all the constructs, (2) the t-values of all paths, (3) and finally the P-value which was obtained by entering $t$-value to the statistical web site www.danielsoper.com. Using tvalue and consequently $p$-value to indicate significance, is widely practiced, and consistent with the recommendations and practices of many studies published in leading IS journals (Lin et al., 2012).

The results show that almost all the hypotheses proposed were supported in our domain study, which reflects the importance of the added factors, organizational culture has a positive impact on both perceived usefulness and perceived personal benefit, and the next paragraph will explain how both relationships are moderated by the gender factor. The individual factors have a positive influence on perceived ease of use, but not on the perceived personal benefit, while the perceived ease of use has a positive impact on the perceived usefulness, which is consistent with the previous studies from literature. Also, the results reveal that perceived usefulness, perceived ease of use and perceived personal benefit all have a significant impact on attitude to use IT, with p-values of 0.00146482 , $0.03718159,0.00014659$ respectively. The attitude, in turn, has a positive impact on the focal construct of this study which is the behavioral intention with tvalue $=4.648$ and $p=0.00000387$. There is also a direct relationship between perceived usefulness and behavioral intention, and this relationship is also significant ( $\mathrm{t}$-value $=5.020, \quad$ and $\mathrm{p}$ value $=0.00000078$ ).

Beside above hypothesis, there are two hypotheses related to the gender factor, which was proposed as a moderator for two paths: the organizational culture to perceived usefulness path, and the organizational culture to the perceived personal benefit path. To test these hypotheses, the data was divided into two data files based on the gender of the respondent, the first file contained the data of all male respondents, and the second contained the female respondents' data. Both files were then loaded to the SmartPLS separately, and the PLS algorithm and bootstrapping were run respectively, and the resulted Path Coefficient $(\beta)$ and t-value were recorded, and the p-value was calculated the same way it was calculated before. The significance of gender as moderator is evaluated by comparing the male and female results, to decide whether the relationship between the underlying constructs is influenced by the gender or not. Table 5 shows the results.

Table 4: Hypotheses testing results summary

\begin{tabular}{ccccc}
\hline Hypothesis & Path Coefficient $(\beta)$ & t-value & p-value & Significance \\
\hline H1: (OC) to (PU) & 0.398 & 5.118 & 0.00000051 & Supported ** \\
H2: (OC) to (PPB) & 0.427 & 5.365 & 0.00000017 & Supported $^{* *}$ \\
H3: (IF) to (PEOU) & 0.315 & 3.923 & 0.00006867 & Supported $^{* *}$ \\
H4: (IF) to (PPB) & 0.154 & 1.481 & 0.07044310 & Not supported \\
H5: (PEOU) to (PU) & 0.465 & 4.833 & 0.00000177 & Supported** \\
H6: (PU) to (AT) & 0.275 & 3.029 & 0.00146482 & Supported ** \\
H7: (PEOU) to (AT) & 0.249 & 1.798 & 0.03718159 & Supported \\
H8: (PPB) to (AT) & 0.426 & 3.716 & 0.00014659 & Supported** \\
H9: (PU) to (BI) & 0.460 & 5.020 & 0.00000078 & Supported** \\
H10: (AT) to (BI) & 0.418 & 4.648 & 0.00000387 & Supported** \\
\hline & ${ }^{*} \mathrm{p}^{*}<.05,{ }^{* *} \mathrm{p}<0.001$ & &
\end{tabular}


Table 5 shows that the positive relationship between Organizational Culture and Perceived Usefulness is stronger in case of men with values $(\beta=0.441$, $t$-value $=4.402>2, p$-value $=0.00001443<$ $0001)$ than it is in the case of women $(\beta=0.359, \mathrm{t}-$ value $=2.199>2, p$-value $=0.01652963$ which is $>0.001$ but < 0.05), which proves H11. The same goes for H12, where by the positive relationship between Organizational Culture and Perceived Personal Benefit is stronger in case of male employees $(\beta=0.474, t$-value $=5.196>2, \quad p$-value $=$ $0.00000061<0001)$ than it is in the case of female employees $(\beta=0.330$, $t$-value $=2.277>2, \quad p$-value $=$ 0.01379544 which is $>0.001$ but $<0.05$ ), and by comparing the results of both cases, it becomes clear that the case of male respondents produces higher significance level than what the female respondents case produces, despite the fact that both cases are considered acceptable statistically.

Table 5: Gender hypotheses results

\begin{tabular}{cccccc}
\hline Hypothesis & & Path Coeff. $(\beta)$ & t-value & p-value & Significance \\
\hline \multirow{2}{*}{ H11:(OC) to (PU) } & Male & 0.441 & 4.402 & 0.00001443 & \multirow{2}{*}{ Supported } \\
& Female & 0.359 & 2.199 & 0.01652963 & \\
H12:(OC) to (PPB) & Male & 0.474 & 5.196 & 0.00000061 & \multirow{2}{*}{ Supported } \\
& Female & 0.330 & 2.277 & 0.01379544 & \\
\hline
\end{tabular}

In summary, the overall results reveal that all the preceding constructs altogether accounts for $65 \%$ of the variance of the focal construct: the behavioral intention of the employees to use IT (R2 $=0.65)$, and out of 12 hypotheses proposed, 11 hypotheses are supported in this study domain, while one hypothesis only was rejected, namely H4: (IF to PPB), Fig. 3, summarizes the results of the tested hypotheses.

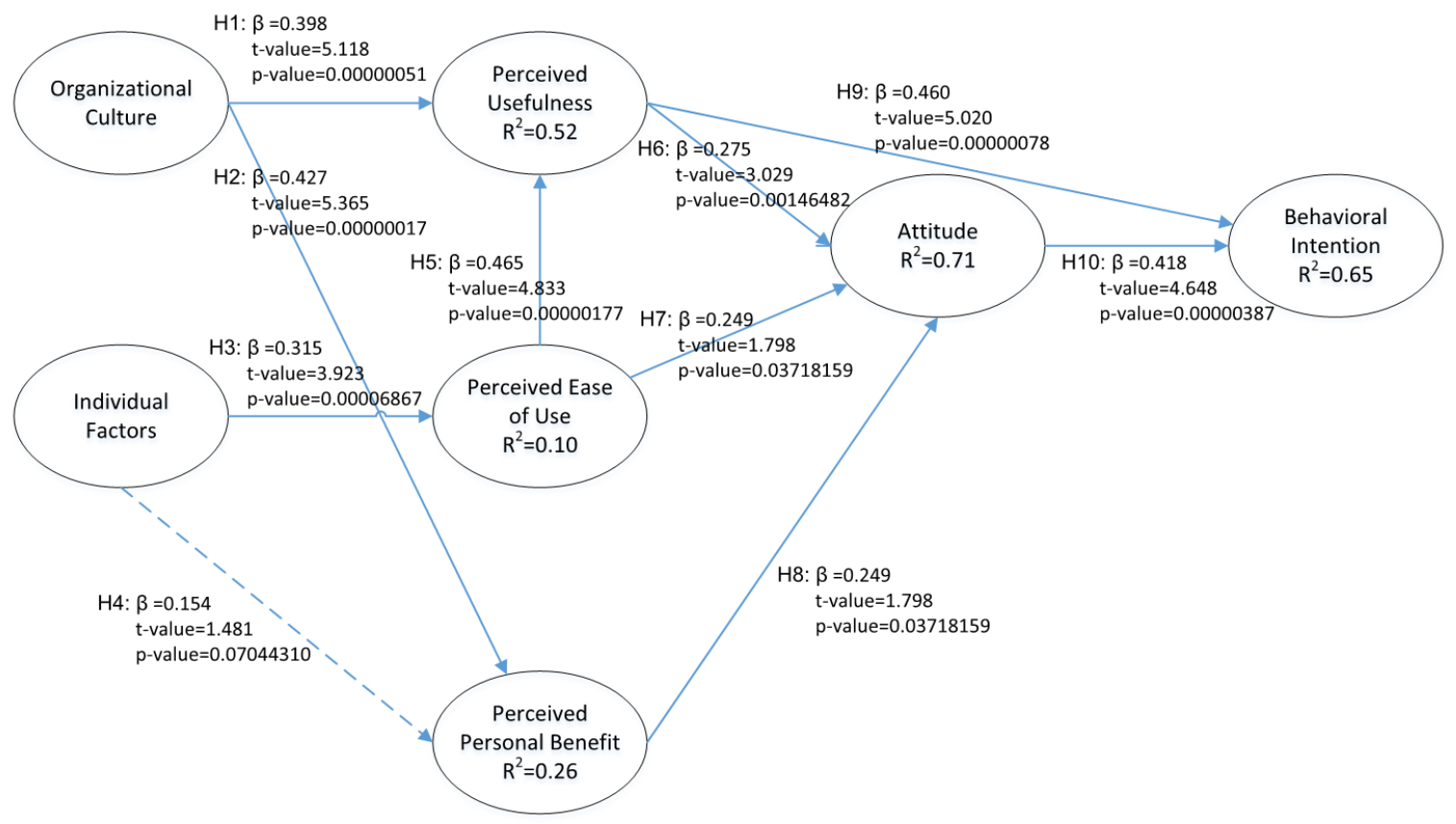

Fig. 3: The SmartPLS results for tested hypotheses

\section{Discussion}

Here, we discuss the research findings, with focus on the hypotheses related to the constructs that was added by this model to the original TAM:

\section{- The relationship between organizational} culture and both perceived usefulness, perceived personal benefit: Both hypotheses 1 and 2 were supported by the above presented results, that means the existence of favorable culture for adopting IT in our public organization causes higher perceived usefulness by the employees and vice versa. Also, it seems that most of the employees' perception of personal benefit is influenced by the organizational culture, this is logical because the personal benefit here was measured by the financial compensation that the employees receive if they use some particular information systems adopted by the ministry in some departments, the prominent culture there has an impact on specifying the amount of such financial compensation, and also on specifying who will receive such compensation. The amount of financial compensation is decided by people from HR department who mostly do not have enough knowledge about IT, also, the selection of people who will use the adopted information systems is not done according to clear criteria, it rather depends on the common practices in the organization such as recommendations from the top management, the candidate relationship with the HR officers, the desire of the head of department being adopting the IS, all these factors 
reflects the importance of prominent organizational culture as a determinant of the personal benefit perception by the employees. It is believed, though, that the correlation between organizational culture and perceived personal benefit will remain valid even if another measurement were used to measure the perceived personal benefit, for example: recognition, or nomination for overseas training, to which the candidates are selected following the same common norms and practices.

- The gender as a moderator of the relationships between organizational culture and perceived usefulness and perceived personal benefit respectively: This study confirmed, empirically, the moderating effect of gender in the perceived usefulness and perceived personal benefit (H11 and H12). The results are consistent with the real situation, in the case of female, the usefulness of the IT is affected by the organizational culture, which usually assign the female employees lower IT jobs, despite their skills or qualifications, and almost all the female employees in IT related jobs are dedicated for data entry and word processing, while more sophisticated IT jobs are usually assigned to male employees. This affects the perception of women regarding their contribution in the improvements that IT brings to the organization, that is, decrease the female's perceive--d usefulness of using IT. This is also true for the perceived personal benefit factor. Since the more sophisticated IT jobs are exclusively assigned to men, and consequently the higher financial compensation goes to them, it is normal then that the female employees have lower perceived usefulness of using IT.

- The relationship between Individual factors and perceived ease of use and perceived personal benefit respectively: The individual factors were found to have a positive impact on the perceived ease of use (H3), this is logical because the employee who was trained adequately on using computer, and who has good computer skills, and with higher educational level which, nowadays, implies studying computer related subjects, is expected to perceive IT as easy to use. However, the study revealed that there is no relationship between individual factors and perceived personal benefit, that is, employees of higher education level, training duration and computer skills do not necessarily perceive IT as useful for their own good. Again, when referring to our study domain, this looks logical, since the IT job assignment and consequently the financial compensation is controlled by the methods that the organization is used to practice (organizational culture) as discussed earlier, rather than by the individual factors, so it is understandable if an individual sees that using IT is beneficial for him because he is satisfied about the financial compensation he receives even if his individual indicators is low according to the above mentioned scales, while other individuals may feel indifferent about using IT because they don't receive decent financial compensation, even though they have better qualifications and skills.

\section{Implications and recommendations}

- Since the study showed the influence organizational culture in determining the employees' perceptions about usefulness of IT, and personal benefits, it is if great importance that IT jobs' assignments, and the gained benefits accordingly, must be decided based on the employee's qualifications, commitment, and productivity and other objective measurements, rather than the currently used subjective factors.

- As the perceived personal benefit was found to be very influential factor on the employees behavioural intention towards IT usage, financial rewards should be used reasonably to motivate employees to better utilize the existing IT; also, other motivators must be used, for example: recognition, abroad training courses, and promotions.

- The study confirmed the vitalness of gender in determining the perceived usefulness and perceived personal benefit for the employees. This implies that qualified women must be enabled to have higher level IT jobs than what they have now, that will enhance the perception of women regarding their contribution in the improvements that IT brings to the organization (perceived usefulness), and regarding their personal interests (perceived personal benefit).

- Many respondents emphasized the importance of continuous, adequate training, this is very relevant to the results of this research, where the skills were not necessarily proportionate with the training, although $74 \%$ of the employees had at least one month of training, $45 \%$ of them classified themselves as beginners in the basic MS windows functions; There is a clear mismatch between the training the employees get and the expected level of efficacy, therefore, both the quality and relevance of training should be revised by experienced trainers together with IT specialists from the ministry.

- One interesting result was that the individual factors do not affect the perceived personal benefit, and since perceived personal benefit was measured by the financial rewards that the employee receives for using IT, it is highly recommended to revise the rewarding policy, employees who are assigned to do more sophisticated IT tasks should be rewarded equivalently, and must be selected based on their qualifications and skills in the first place.

\section{Research contribution and conclusion}

This study investigated the determinants of user acceptance of technology in the Yemeni public sector, as an attempt to overcome the 
underutilization of IT/IS. A model was developed and tested, and data were collected quantitatively through a questionnaire distributed to 139 employees. The results showed the significance of organizational culture and perceived personal benefit in driving the users' intention towards the IS. It was also showed that gender was influential in determining employees perceived personal benefit and perceived usefulness. The model accounts for $65 \%$ of the variance in the dependent variable: behavioral intention, which expresses a good predictivity power. The contribution of the present research is twofold. First, within the context of public sector in Yemen it attempts to enrich the managerial knowledge by increasing the awareness about user acceptance and its importance as a major success factor in IT/IS implementation and utilization, in a way that leads to better practices in the future projects.

Secondly, the study enriched the literature of technology acceptance by presenting a study that investigated the technology acceptance in a context that has been rarely investigated by previous studies, whereby lower focus was given to public organizations, and even lower focus to public sector organizations in developing, third world countries. Therefore this study has attempted to fill in this gap by examining user acceptance in the public sector of an Arabic country that has been classified by the UN (ITU, 2011) as one of the least developed countries. The study provided an empirical evidence for the importance of the construct perceived personal benefit presented by (Hamner and Qazi, 2009), which is influenced by the organizational culture. It also proved empirically, the significance of gender in leading the employees' perceptions about their personal benefit and the system's usefulness; this is one of the biggest contributions of this research, as many of the previous studies didn't address this issue, which has been found to have significant influence in the context of third world, Arabic countries.

Finally, this study was conducted in one of the biggest departments in the Yemeni government (MoSAL), further research is required to generalize the results to other ministries, considering other factors that might not be covered by this study. For instance, the proposed model did not cover any factors related to technical issues or infrastructural problems, because most of the previously implemented information systems and their tools and equipment's were procured and maintained by the donors' organizations, this limitation should be taken into consideration when applying the results of this study to other public organizations.

\section{Acknowledgment}

The authors would like to thank Universiti Sains Malaysia (USM) as this research has been supported by the Research University Grant (RUI) [Account Number: 1001/PKOMP/811251]

\section{References}

Ajzen I (1991). The theory of planned behavior. Organizational Behavior and Human Decision Processes, 50(2): 179-211.

Awang Z (2012). Structural equation modeling using AMOS graphic. Universiti Teknologi MARA, Selangor, Malaysia.

Chandio FH (2011). Studying acceptance of online banking information system: A structural equation model. Ph.D. Dissertation, Brunel Business School, Brunel University London, London, UK.

Chin WW (1998). The partial least squares approach to structural equation modeling. Modern Methods for Business Research, 295(2): 295-336.

Chuttur MY (2009). Overview of the technology acceptance model: Origins, developments and future directions. Sprouts: Working Papers on Information Systems, 9(37): 1-21. Indiana University, USA.

Davis FD (1989). Perceived usefulness, perceived ease of use, and user acceptance of information technology. MIS Quarterly, 13(3): 319-340.

Dijk AJV (2009). Success and failure factors in ICT projects: A Dutch perspective. Ph.D. dissertation, Middlesex University, London, UK.

Dubey R, Gunasekaran A, Helo P, Papadopoulos T, Childe SJ, and Sahay BS (2017). Explaining the impact of reconfigurable manufacturing systems on environmental performance: The role of top management and organizational culture. Journal of Cleaner Production, 141: 56-66.

Farrell AM and Rudd JM (2009). Factor analysis and discriminant validity: A brief review of some practical issues. In the Australia and New Zealand Marketing Academy Conference, Melbourne, Australia.

Fishbein M and Ajzen I (1975). Belief, attitude, intention, and behavior: An introduction to theory and research. AddisonWesley, Reading, Boston, USA.

Gefen D and Straub DW (2000). The relative importance of perceived ease of use in IS adoption: A study of e-commerce adoption. Journal of the Association for Information Systems, 1(1): 8-30.

Hair JF (2014). A primer on partial least squares structural equation modeling (PLS-SEM). Sage Publications, London, UK.

Hair JF, Ringle CM, and Sarstedt M (2011). PLS-SEM: Indeed a silver bullet. Journal of Marketing theory and Practice, 19(2): 139-152.

Hamner M and Qazi RuR (2009). Expanding the technology acceptance model to examine personal computing technology utilization in government agencies in developing countries. Government Information Quarterly, 26(1): 128-136.

Ifinedo P (2011). Examining the influences of external expertise and in-house computer/IT knowledge on ERP system success. Journal of Systems and Software, 84(12): 2065-2078.

Igbaria M and Chakrabarti A (1990). Computer anxiety and attitudes towards microcomputer use. Behaviour and Information Technology, 9(3): 229-241.

ILO (2014). Labour force using WB population estimates. International Labour Organization, Genève, Switzerland. Available online at: www.ilo.org

ITU (2011). Least developed countries (LDC). International Telecommunication Union, Genève, Switzerland. Available online at: www.itu.int

Jarvenpaa SL, Tractinsky N, and Vitale M (2000). Consumer trust in an internet store. Information Technology and Management, 1(1-2): 45-71.

Ko DG, Kirsch LJ, and King WR (2005). Antecedents of knowledge transfer from consultants to clients in enterprise system implementations. MIS Quarterly, 29(1): 59-85. 
Krejcie RV and Morgan DW (1970). Determining sample size for research activities. Educational and Psychological Measurement, 30(3): 607-610.

Lin TC, Wu S, and Lu CT (2012). Exploring the affect factors of knowledge sharing behavior: The relations model theory perspective. Expert Systems with Applications, 39(1): 751764.

MacKenzie SB, Podsakoff PM, and Podsakoff NP (2011). Construct measurement and validation procedures in mis and behavioral research: Integrating new and existing techniques. MIS Quarterly, 35(2): 293-334.

Mathieson K, Peacock E, and Chin WW (2001). Extending the technology acceptance model: the influence of perceived user resources. ACM SigMIS Database, 32(3): 86-112.

Nawi HAS, Rahman AA, and Ibrahim O (2011). Government's ICT project failure factors: A revisit. In the International Conference on Research and Innovation in Information Systems, IEEE, Kuala Lumpur, Malaysia: 1-6. https://doi.org/10.1109/ICRIIS.2011.6125738

RAEng (2004). The challenges of complex IT projects. The Royal Academy of Engineering, London, UK. Available online at: www.raeng.org.uk

SGII (2014). Chaos report. The Standish Group International Inc., Boston, USA. Available online at: https://www.standishgroup.com/
Shipley B (2000). Cause and correlation in Biology: A user's guide to path analysis, structural equations, and causal inference. Cambridge University Press, Cambridge, UK.

Steel RG and James H (1960). Principles and procedures of statistics: With special reference to the biological sciences (No. 519.5 S314p). McGraw-Hill, New York, USA.

TSG (2015). Chaos Report. TSG International, Armidale Australia. Available online at: https://tsg.international/

Venkatesh V and Davis FD (2000). A theoretical extension of the technology acceptance model: Four longitudinal field studies. Management Science, 46(2): 186-204.

Wahdain EA and Ahmed M (2015). Examining the determinants of users' acceptance of IT in the Yemeni public sector: pilot study. In the $1^{\text {st }}$ ICRIL-International Conference on Innovation in Science and Technology, Universiti Teknologi Malaysia, Kuala Lumpur, Malaysia: 373-376. Available online at: http://eprints.usm.my/33139/

Wahdain EA, Ahmad MN, and Zakaria NH (2014). Using TAM to study the user acceptance of IT in the Yemeni public sector. International Journal of Computer and Communication Engineering, 3(3): 160-165.

Xu Lu DV (2008). Factors influencing the adoption of mobile learning. In the $19^{\text {th }}$ Australasian Conference on Information Systems, Christchurch, New Zealand: 597-606.

Yeo KT (2002). Critical failure factors in information system projects. International Journal of Project Management, 20(3): 241-246. 